\title{
Criticality analysis of a country's transport network via an agent-based supply chain model
}

\author{
Célian Colon $\oplus^{1 凶}$, Stéphane Hallegatte $\circledast^{2}$ and Julie Rozenberg ${ }^{2}$
}

\begin{abstract}
Building resilience against shocks has become a pillar of sustainability. By understanding how the different components of an economy interact in times of crisis, we can design resilience strategies that go beyond building walls or dams. We formulate an original agent-based model to explore a crucial pathway through which a disaster affects the economy: the transport-supply chain nexus. The model simulates the behaviour of firms facing transport and supply disruptions and estimates the resulting indirect losses. As an illustration, the model is used to assess the criticality of Tanzanian roads, which are vulnerable to floods. We report three main results. First, the model generates maps that identify the transport infrastructure assets that are most critical for specific supply chains: roads that are most important for food security are different from those supporting international trade, for instance. Second, economic losses from transport disruptions increase non-linearly with the duration of disruptions, highlighting the benefit from fast repairs. Third, by combining economic and transport modelling, we can consider a broader spectrum of interventions. Beyond strengthening the transport system, it is also possible to make supply chains more resilient to disruption with, for instance, sourcing decisions or inventory management.
\end{abstract}

B uilding resilience against disasters has become a key adaptation strategy for climate change. But our ability to adequately track the impact of disasters has remained limited. Disasters are still often estimated by summing up reconstruction $\operatorname{costs}^{1,2}$ without considering the broader implications for the functioning of the economic system. This approach gives little insight into the real economic role of specific assets and the complex propagation of the shock through supply chains. It is likely to lead to substantial underestimates of the severity of disasters ${ }^{3}$.

Transport systems in particular play a key role during and after disasters because of the combination of their high vulnerability and their importance for the functioning of the rest of the economic system. Because transportation systems have become extremely efficient and reliable, economies have become increasingly dependent on them. Also, because transportation infrastructure assets are by nature localized, they are affected very heterogeneously by natural disasters and, in turn, affect the rest of the economy very heterogeneously. Two bridges may be of equal engineering quality and construction cost and may experience the same damages (defined as the repair cost), but the economic implications of closing each bridge during the reconstruction might be completely different. One bridge might be playing a vital role in the local economy (for example, the Bay Bridge in California ${ }^{4}$ ) while the other one might be redundant, making it possible to close it without notable economic impacts.

We propose a model that improves our ability to understand and assess the economic consequences of natural disasters by analysing the transport-supply chain interactions in space and time. Our model allows us to track how the disruption of transport nodes or links perturbs the flows of goods in supply chains and how these perturbations then affect households, firms and trade. This model is a new tool for evaluating the implications of transport disruptions, identifying bottlenecks and planning for resilience. It innovates by bridging two recent developments, namely, transport network study and firm-level input-output analysis, that used to be considered in isolation.
In the last decade, increasing efforts have been made to quantify the resilience of transport systems to natural disasters and use this information to inform decision makers. However, most of the available tools to assess the impact of disruption in transport systems rest on network theory and the concept of percolation ${ }^{5,6}$. Based on data on vehicles, passengers and freight, impacts are measured by the increase in travel time ${ }^{7}$, loss of accessibility ${ }^{8}$ or quantities of blocked flows ${ }^{9,10}$. Such indicators can then inform infrastructure planning ${ }^{11}$.

But the economic impact of disrupted transport infrastructure does not end there. Transport disruptions translate into supply chain disruptions that act as amplifiers of disaster-induced economic shocks ${ }^{12}$. Multiple case studies provide detailed accounts of the propagation mechanisms, including studies of the 2011 Töhoku earthquake in Japan ${ }^{13-15}$ and the 2011 floods in Thailand ${ }^{16,17}$. These mechanisms are often studied using input-output models ${ }^{18-20}$, computable general equilibrium models (CGEs) ${ }^{21}$ or hybrid models ${ }^{22}$. Some of these models explicitly represent the transport sectors to capture the impact of transport infrastructure destruction on the rest of the economy ${ }^{23,24}$.

However, the level of aggregation of standard models is problematic, and the explicit representation of firm-level interactions is preferable $^{25}$. According to case studies, the cascades of disruptions are due to specific patterns of interdependencies between firms rather than sectors $^{15,26,27}$. Heterogeneities among firms and in production networks have the potential to amplify localized shocks ${ }^{28-32}$. Aggregated models also have limited applicability for planning purposes because they cannot capture the role of specific transport nodes or edges.

This paper brings together the firm-level input-output approaches with transport network analysis. We argue that firm-to-firm models cannot satisfactorily assess the impacts of a disaster without considering how goods and services are transported. Likewise, transport system models cannot assess the criticality of a transport link without considering the type of goods and services it transports and its role in connecting suppliers and clients. Our models contribute to the literature by combining these two approaches into an integrated assessment framework. 
Our model builds on Henriet et al. ${ }^{31}$. They developed a firm-to-firm model and showed that estimated losses from natural disasters were much larger when firm-level dynamics were considered. Inoue and Todo ${ }^{33}$ extended and applied this firm-to-firm model with a comprehensive dataset of the supplier-buyer linkages of Japan. Their model better reproduces the macroeconomic trajectory that followed the 2011 Tōhoku earthquake than aggregated input-output models. Our work adds the transport network layer to this model. From a transport analysis perspective, Kim et al. ${ }^{34}$ and Ham et al. ${ }^{35}$ mapped flows of commodities on the highways and railways of the United States and estimated the increase in transport costs due to the disruption of highway links. Our work extends this approach by modelling the behaviour of firms and the cascades of impacts throughout supply chains. It shares similarities with the work of Tatano and Tsuchiya ${ }^{36}$, who analysed the impact of the disruption of the main highways and railways of Japan using a multiregional CGE model, but our model has a finer spatial and economic granularity.

The model is applied to the United Republic of Tanzania. Combining data on the transport sector from Pant et al. ${ }^{9}$ and OpenStreetMap contributors ${ }^{37}$, the input-output table for the coun$\operatorname{try}^{38}$, a listing of Tanzanian firms with their basic characteristics and the results of a dedicated firm survey that collected data on inventories and vulnerability to disruptions ${ }^{39}$, we created a supply chain model that fully embeds the transport network ${ }^{40}$. A set of firmsone per sector-is modelled on each important node of the transport network, along with households, who buy firms' outputs. Each firm buys inputs from and sells outputs to other firms located in the other nodes of the transport network. Firms are also connected to international suppliers and buyers, modelled at the country's main entry and exit points. Extended Data Fig. 1 illustrates the coupling of the supply chain and transport networks.

In normal times, suppliers provide intermediate goods to other firms using the least-cost path on the road network. This journey is associated with a transport cost that is paid for by the client. When a road gets disrupted, two scenarios can unfold. If there is an alternative, more expensive path, the increase in transport cost is transferred to the client and propagated further, leading to an increase in the final price paid by consumers. If there is no other path and the client cannot receive goods from the supplier on time, then the lack of input can (1) be compensated for by other suppliers, (2) be smoothed using inventories or (3) reduce the client's production. Shortages then propagate along supply chains and may eventually lead to drops in final consumption.

The final macroeconomic cost (that is, indirect losses) is estimated as the sum of two impacts: (1) the increased cost for final consumers, which is equal to the sum of all the incremental transportation costs in the economic system, and (2) the value of 'missing goods and services' valued at their pre-shock price, which is a conservative estimate of the impact on consumers and therefore of the welfare losses. At this stage, the model does not distinguish between consumers in a given location (for example, by income class) and does not represent consumers' behavioural response when prices change or goods are not available.

We use our model to assess the criticality of the road network of the United Republic of Tanzania, motivated by the vulnerability of this economy to floods caused by heavy rainfalls or tropical storms. According to the World Bank's observers, the country is subject to small, frequent floods, which often interrupt roads for a few days, but also to larger floods that severely damage the transport network, which then takes very long to get repaired. Pant et al. ${ }^{9}$ reported 13 such sizeable transport-disrupting events between 2014 and 2016. Using a comprehensive set of scenarios, we estimate the indirect economic losses caused by road disruptions for the country's households and international buyers. We draw maps that show the criticality of each node and link in the transport network, which can help prioritize intervention to mitigate flood impacts. The main behaviour of the model is then analysed, especially the crucial role played by the duration of the transport disruptions and the differentiated vulnerability of different supply chains. The model helps assess a variety of interventions able to reduce economic losses from road disruptions and build resilience.

\section{Results}

First, we simulate a 1 week disruption of each transport infrastructure asset (that is, the nodes and edges of the transport network) one by one and show the resulting economic impacts on the transport map. When all supply chains are considered, these criticality maps show the criticality of transport infrastructure for the overall economy, including the producers and consumers located in different regions. But if we represent the losses related to selected products only, such as food, we can generate criticality maps for specific supply chains. The four maps of Fig. 1 show, for four products, the aggregate cost (for all Tanzanian consumers, irrespective of where they live) resulting from a 1 week disruption of each road and bridge. There is uncertainty in the supply chain network, which is reconstructed based on aggregate data and with some randomness in the firm-to-firm connections, so we reproduce the same exercise on ten different networks to confirm the stability of the criticality maps.

These maps highlight the first finding of this paper: the criticality of an infrastructure asset is highly dependent on the product that is considered. For example, the roads and bridges that are important for food security may not be important for services. The criticality of an asset depends on its users ${ }^{3}$.

For example, the criticality map of the United Republic of Tanzania for agricultural products, shown in Fig. 1a, reveals that the supply chains underpinning those products are relatively less impacted by transport disruptions. The map is different when we consider food products-here, food products consist of processed products (for example, sugar), whereas agricultural products are unprocessed (for example, sugar cane). The production and consumption of food products rely much more on the transport system. For some of the most critical roads, a 1 week disruption can induce a $1.5 \%$ to $2 \%$ decrease in national daily consumption of food products (Fig. 1b).

The northeast-southwest corridor, which connects the port of Dar es Salaam to Zambia and, further, to the Democratic Republic of Congo, is particularly critical to international trade (Fig. 1d). These roads carry large amounts of freight from and to Central African countries. Plans to redevelop (currently unreliable) rail freight between Dar es Salaam and Zambia are likely to reduce such criticality ${ }^{41}$.

This first result confirms the value of connecting a supply chain model to a transport model and suggests that traditional criticality analyses of the transport system, which consider the transport network but not its users, may fail to identify the right priorities for intervention.

The second general insight from these simulations is that the economic impact increases non-linearly and extremely quickly with the duration of transportation disruptions. The temporary rerouting of freight flows triggered by 1 week disruptions mostly drives indirect economic losses (Fig. 2). Thanks to inventories, there are almost no shortages or business interruptions and losses remain limited.

But if disruptions last longer, some firms start to run out of inventories and are forced to delay their deliveries, leading to cascading impacts and scarcity of final goods and services. Scarcity impacts welfare much more than an increase in prices due to rerouting. A 2 week disruption is, on average, five times costlier than a 1 week one. The longer the disruption, the further shortages propagate in the supply chains. A 4 week disruption is on average 24 times costlier than a 2 week one. 


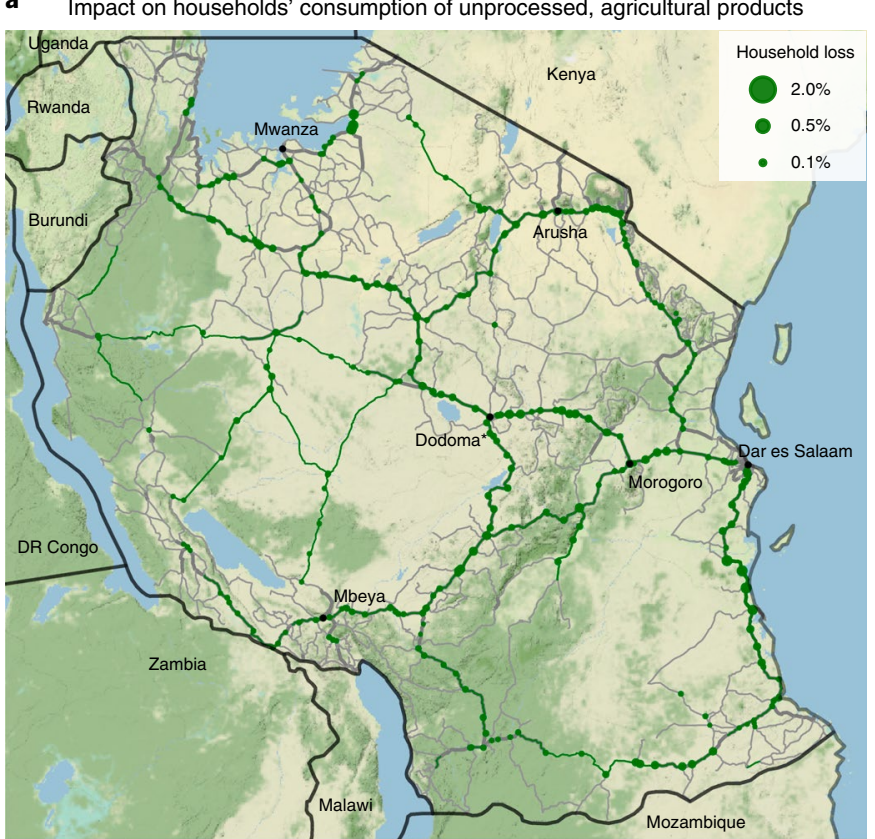

c

Impact on households' consumption of products from the manufacturing sector

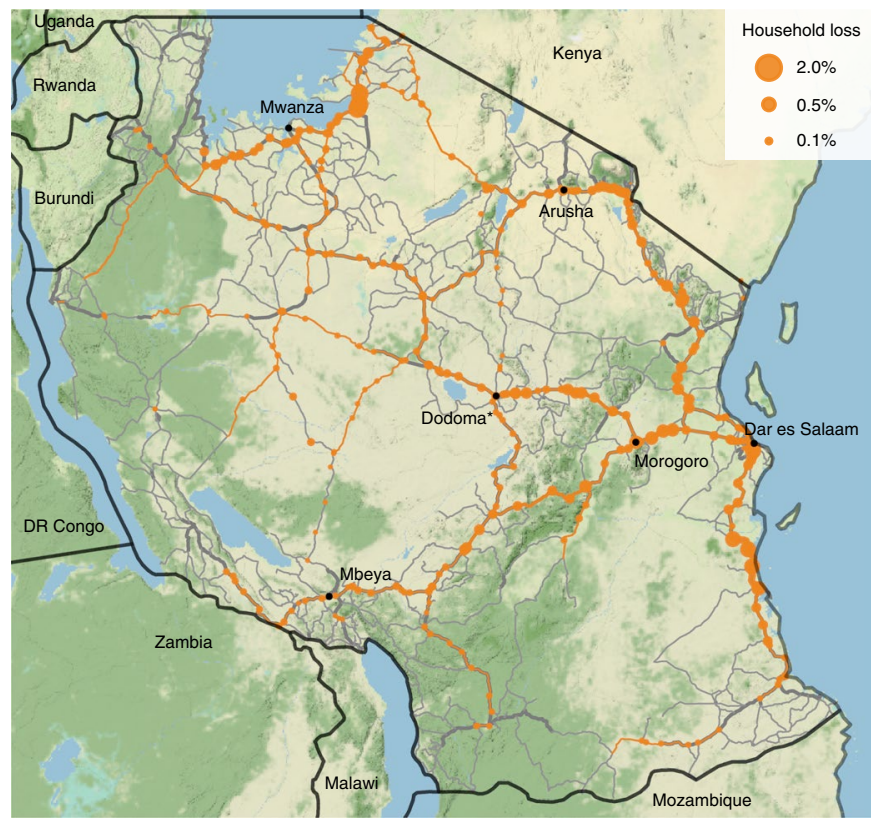

b

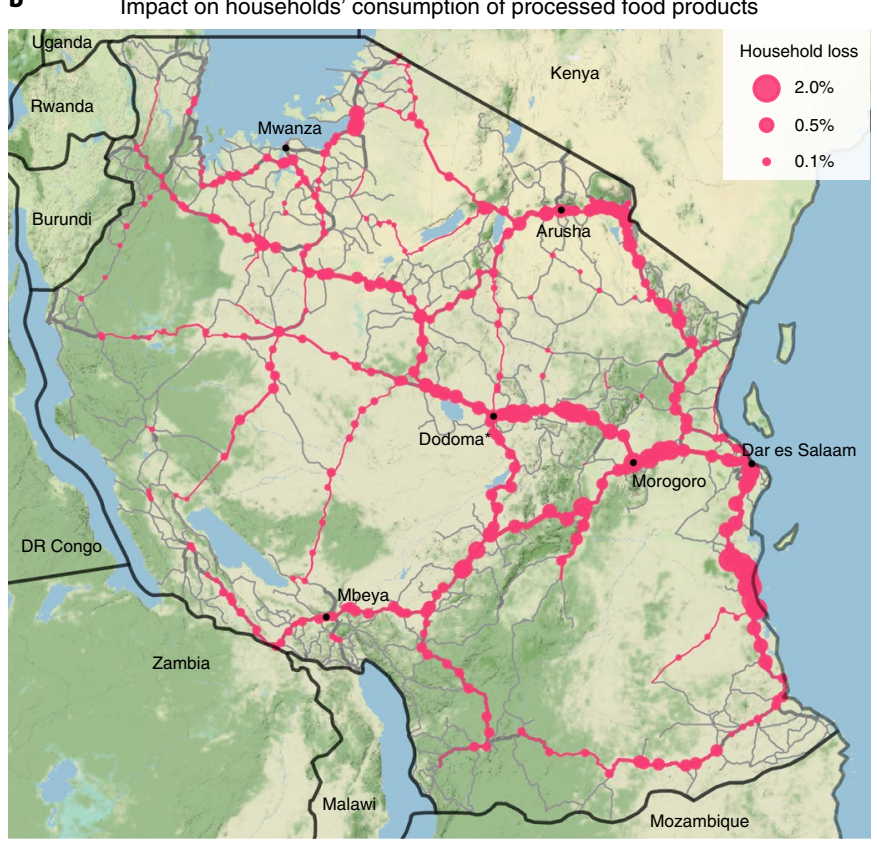

d

Impact on international buyers purchasing goods produced in the United Republic of Tanzania (exports) or transported through the country (transit)

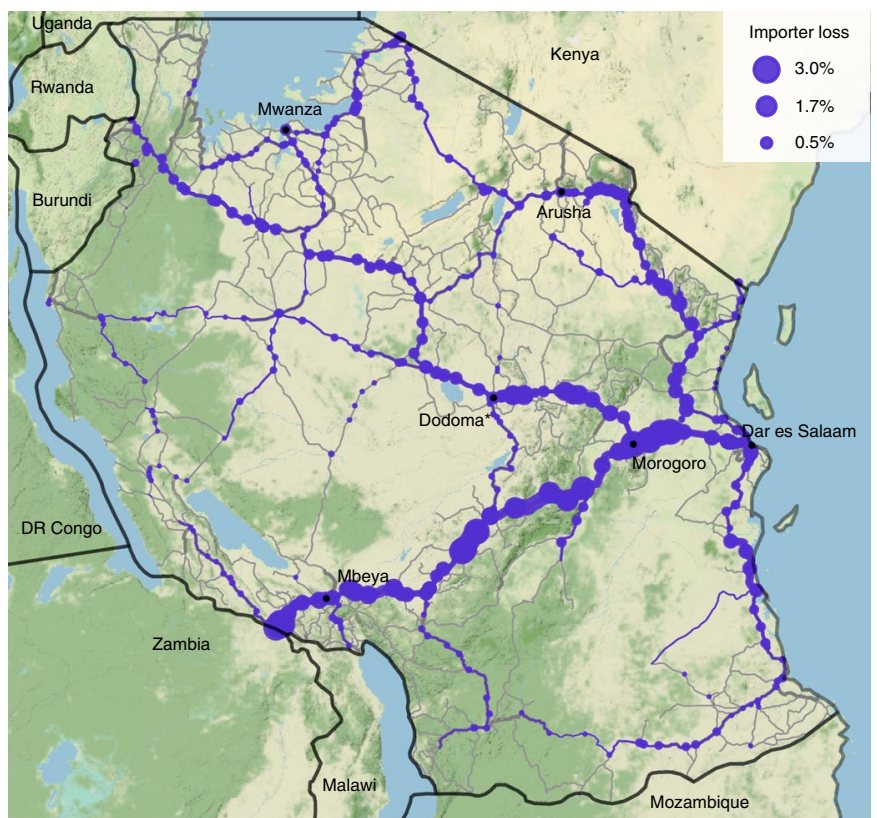

Fig. 1 | Criticality patterns change according to the type of supply chain. Impacts are estimated using 1 week disruptions and averaged over ten different network reconstructions. a-c, The indirect losses incurred by Tanzanian households, expressed in loss of daily consumption of agricultural products (a), processed food (b) and manufactured products (c). Impacts are propagated along the Tanzanian supply chains down to final consumers. d, The estimated indirect losses due to price increases for international buyers of products produced in the United Republic of Tanzania or of products transiting through the country. The model does not incorporate supply chains outside of the country, such that losses in $\mathbf{d}$ are estimated for the direct buyers and not the final consumer. They are expressed as a percentage of daily imports. National borders are shown as thick black lines; roads are shown as thin grey lines. The capital city, Dodoma, is flagged with an asterisk. Map tiles by Stamen Design, under a Creative Commons Attribution (CC BY 3.0) license. Data by OpenStreetMap, under the Open Data Commons Open Database License (ODbL).

This observation leads to the third insight from this modelling exercise. Improving resilience can be done by strengthening the transport system (supply-side action), but also by making the users of this system better able to manage disruptions (demand-side action).

To illustrate these two approaches, we define three interventions for each and compare their potential for reducing the indirect losses of road disruptions (Fig. 3). We target two critical corridors identified in Fig. 1 and shown in Extended Data Fig. 2: a portion of the T1 road south of Dodoma and a portion of the T7 road on the east coast. Together, the two segments represent $181 \mathrm{~km}$ of trunk roads. We consider (i) strengthening them to reduce their vulnerability to floods, (ii) increasing redundancy by building new roads in the 


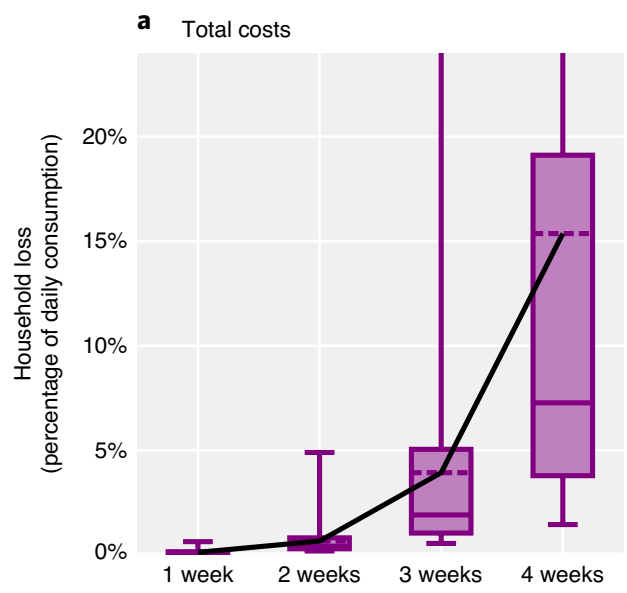

b Price effect

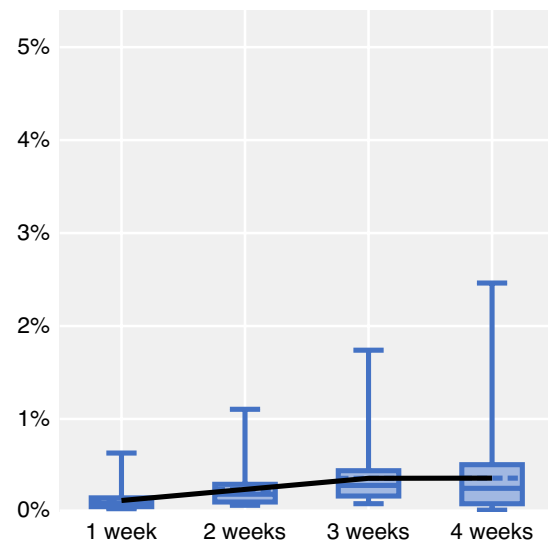

c Shortage effect

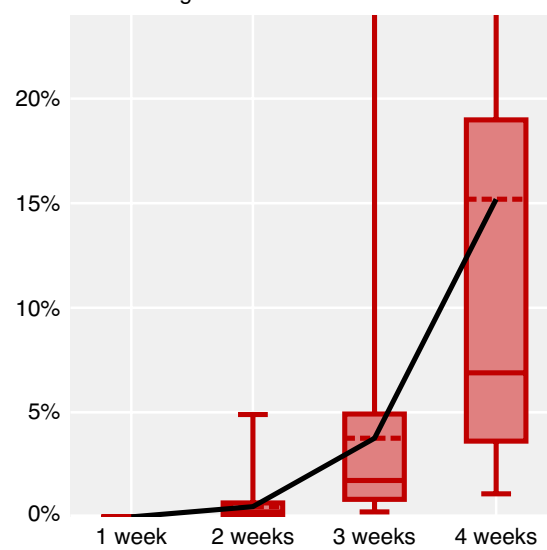

Fig. 2 | Supply chain impacts on households triggered by disruptions of various durations. a, Total losses. b,c, Here the two kinds of losses are disentangled into those attributed to an increase in transportation costs (b) and those due to shortages (c). The results represent a distribution of impacts obtained by disrupting the 300 most critical transportation nodes per duration category. The filled rectangles indicate the interquartile intervals, the solid horizontal lines indicate the medians and the horizontal dashed lines indicate the means. Mean values are joined with a black curve. The vertical lines extend to the minimum and maximum of the distributions; when the maximum lies outside the plotting area, as in $\mathbf{a}$ and $\mathbf{c}$, the upper part of the vertical line is not capped.

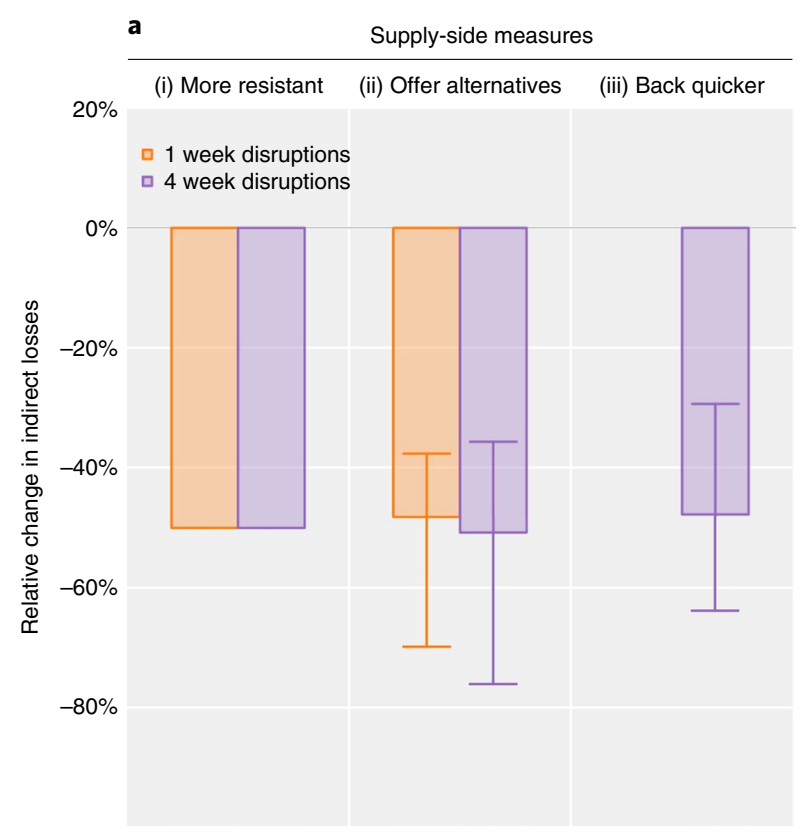

\begin{tabular}{ll} 
b & Demand-side measures \\
\hline (i) More inventories & (ii) More suppliers $\quad$ (iii) Closer suppliers
\end{tabular}

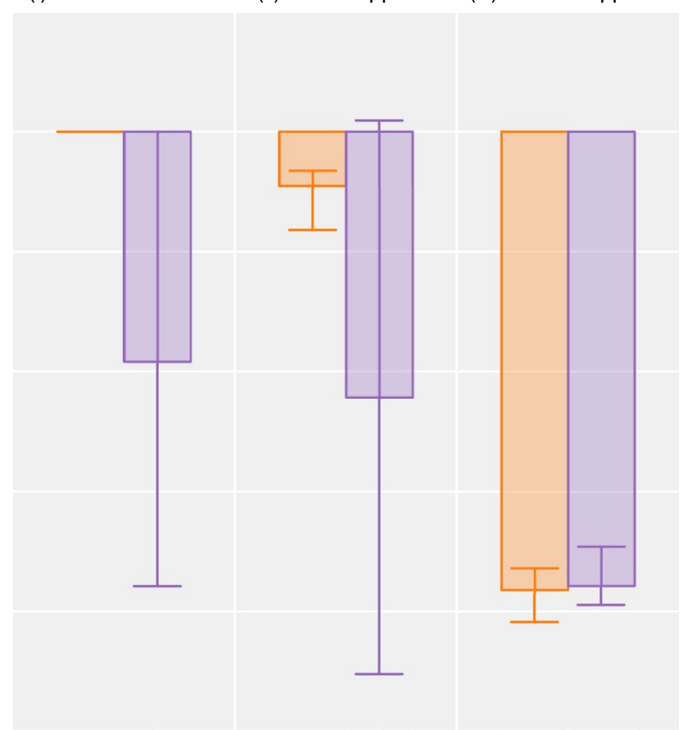

Fig. 3 | Balancing supply-side and demand-side measures to promote resilience. Comparison of interventions aimed at reducing the indirect impact of disasters affecting the two critical corridors highlighted in purple in Extended Data Fig. 2. a, Three supply-side measures. (i) These $181 \mathrm{~km}$ of roads are made more resistant to disasters: they have a $50 \%$ chance of getting disrupted if a disaster hits instead of a $100 \%$ chance. (ii) New roads are built to offer alternative routes; see Extended Data Fig. 2 for details. (iii) Recovery services are improved such that 4 week disruptions are reduced to 3 weeks. b, Three demand-side measures. (i) All firms hold one more week of inventories (that is, 5.5 weeks on average instead of 4.5). (ii) All firms have two suppliers per type of inputs instead of one. (iii) The distance between suppliers and buyers is on average $60 \mathrm{~km}$ instead of $190 \mathrm{~km}$ (obtained by increasing the weight put on distance when firms choose suppliers; see Supplementary Methods). Changes in indirect losses are estimated using 1 week disruptions, shown in orange, and 4 week disruptions, shown in purple. Each bar represents the distribution of changes in indirect losses for the 11 nodes and 9 edges that compose the highlighted routes, averaged over ten network reconstructions. Each rectangle extends to the mean of the distribution, and the vertical line with capped ends indicates the interquartile interval.

area and (iii) improving preparedness so that road damages can be repaired more quickly, thereby reducing the duration of disruptions.

Figure $3 \mathrm{a}$ shows that these three actions that provide similar benefits in terms of avoided final losses. Strengthening the road with wider culverts and better materials could halve the likelihood of disruption. According to Miyamoto International ${ }^{42}$, building a more robust road would cost about $2 \%$ to $4 \%$ of the US $\$ 1$ million per $\mathrm{km}$ construction cost estimated for such roads ${ }^{43}$. Therefore, the incremental cost of the strengthening strategy would amount to US $\$ 3.6$ million to US $\$ 7.2$ million, provided that the strengthening is done at the construction stage (retrofitting the road would be much more expensive). Building about $200 \mathrm{~km}$ of new roads to offer an 
alternative corridor could lead to similar benefits, at a much higher cost of about US $\$ 200$ million. These two estimates are likely to be heavily dependent on the country's topography.

Interestingly, the same reduction in indirect losses could be achieved without capital investment by reducing the disruption duration from 4 weeks to 3 weeks, using, for instance, better monitoring and reporting of road damages and quicker dispatch of staff and equipment. Since better monitoring and maintenance of roads is widely considered cost-effective ${ }^{44}$, by reducing the need for major works, this intervention may well have a negative cost even without considering resilience gains.

Another approach to reducing the cost of transport disruptions is to ensure that firms can manage them better. This resilience can be strengthened through (i) larger inventories, (ii) a larger number of suppliers per firm or (iii) reducing the distance between suppliers and buyers - that is, adopting local-sourcing strategies. Figure $3 \mathrm{~b}$ shows the loss-mitigating potential of these measures on the two targeted corridors, while Extended Data Fig. 3 shows the impact of the same measures on the 300 most critical transport nodes.

Figure $3 \mathrm{~b}$ shows that having one extra week of inventory significantly reduces the losses triggered by the prolonged disruption of these roads, as does having two suppliers per input instead of one. Those measures are, however, most effective for long disruptions, since firms already have enough inventory to manage one-week disruptions (according to the firm survey realized for this study). It may be the case that they have such large inventories because of the regular transport disruptions in Tanzania, a response identified in other countries ${ }^{45}$. Extended Data Fig. 3 shows that these results are valid for all assets: holding larger inventories and having more suppliers massively reduce losses for large disasters.

In Fig. 3b, local-sourcing strategies massively reduce losses for both short and long events. When the average distance between supplier and buyer is reduced, less freight is being transported on the two considered corridors. That way, disrupting these roads generates fewer perturbations and induces fewer losses. But, as shown in Extended Data Fig. 3, this result is not valid everywhere. In general, local-sourcing strategies reduce the indirect losses of short disruptions but increase those of long ones. Relying on local suppliers and clients reduces the need for transport and exposure to distant transport-disruption disasters. But when local disaster hits all suppliers and clients simultaneously, a consequence of local sourcing, then interdependency across firms makes the recovery longer and more difficult. Had they maintained relationships with distant suppliers and clients, they would be able to source inputs and sell products as soon as transport returned to normal (something observed empirically after the 2011 earthquake in $\operatorname{Japan}^{14}$ ).

\section{Discussion}

We combine a geospatially disaggregated firm-level input-output model with a model of the Tanzanian transport network to analyse the full economic criticality of each road segment. This coupling highlights how different supply chains have different exposures to transport disruptions and amplify those shocks differently. As a result, sector-specific criticality maps exhibit different patterns. The bottlenecks for food security will not be the same as those for trade competitiveness.

Quantifying criticality in this way can inform investment decisions. Strengthening infrastructure assets can reduce disaster losses, but with limited resources to allocate to infrastructure ${ }^{46}$, it is crucial to prioritize the most critical assets for the economic system's functioning. Doing so requires considering not only construction costs and transport flows but also accounting for the criticality of the assets (that is, their importance for various sectors of the economy). Overlaying hazard flood maps with our criticality maps (Fig. 1) would provide priorities for making new roads and bridges more resistant to floods.
But resilient infrastructure systems do not only rest on stronger assets. As seen in Fig. 2, each additional day of disruption gets increasingly costly. This fast and non-linear increase in indirect costs with disruption duration results from the interplay between transport continuity and inventory management. It is a general result and is not specific to the country investigated. It is consistent with Henriet et al. ${ }^{31}$ and Inoue and Todo ${ }^{33}$, who show that firm-level input-output models exhibit larger cost amplification effects than sector-level ones. We obtain a similar behaviour in Extended Data Fig. 4. The fast increase also highlights how crucial inventories are in the resilience of the manufacturing sector. Building the capacity to quickly restore services on damaged roads or bridges ${ }^{47}$ can generate the same economic benefits as building more or stronger roads-but at a lower cost.

Managing transport demand by reorganizing supply chains is also an option for coping with disasters. Such an approach is rarely considered in disaster risk management, which primarily addresses direct impacts and often focuses on the supply of infrastructure services. As expected, adding inventories and double-sourcing strategies significantly reduces indirect costs. The model can be used to identify the type of inputs for which additional safety stocks would be most beneficial for a country. Preliminary results, shown in Extended Data Fig. 5, suggest that food products are particularly critical for the United Republic of Tanzania. Such inventories are, however, costly due to storage needs and the risk of wastage, which is particularly acute for perishable goods ${ }^{45}$. Further analyses could help identify where such inventories are most needed and which firms are most critical in propagating impacts.

Relying on local suppliers and clients has a mixed effect. It largely reduces the need for transport and thus the exposure to disasters. But failing to keep relationships with distant partners can severely aggravate the losses. This result, which we expect not to depend on the specific country investigated, is consistent with findings related to the 2011 Tōhoku earthquake ${ }^{14}$ and Hurricane Sandy ${ }^{48}$. It feeds into the globalization-versus-relocation debate, which has garnered increasing interest since the COVID-19 crisis began (see, for example, the work of Baldwin and Evenett ${ }^{49}$ ). Our results suggest that relocating supply chains can boost resilience only if global ties are maintained to help manage local shocks.

The resilience agenda tends to focus on building more and stronger infrastructure, while many countries do not have the fiscal space to pay for all the infrastructure they need. Instead, our model highlights 'soft' interventions focused on improving the maintenance and accelerating the repairs of infrastructure assets, possibly delivering resilience at much lower costs. Furthermore, working with the users of infrastructure services, as suggested by Hallegatte et al. ${ }^{3}$, can also offer opportunities to build resilience at an affordable cost, even in poor environments.

Our main conclusions - the criticality maps, superlinear reaction to disruption duration and importance of comparing supply-side and demand-side interventions-are robust, but the quantified estimates from this study have large uncertainties. These uncertainties are due to the poor quality of the data, the probabilistic reconstruction of the supply chains, cut-offs in the number of firms and transport nodes and behavioural assumptions in the firm model (Supplementary Table 11). Better calibration and validation will be critical to improving the model, but this will require dedicated data collection and post-flood firm surveys to measure the firm-level impacts.

The model can also be improved in several directions. Although service sectors are included in the model, their operations are assumed to be independent of the transport network. This simplification allowed us to focus on freight but dwarfed the role played by service firms in connecting supply chains, such as third-party logistic providers. The impact of disasters on workers' ability to reach workplaces is an important source of economic losses and 
is not explicitly considered in the current version of the model. Finally, the model relies on simple input-output mechanisms and cost-minimizing behaviour, which do not include the (limited) possibility of substituting inputs for each other during a crisis. The importance of these mechanisms is evident when comparing different purchasing responses from firms (the 'reactivity rate' in the Supplementary Methods). And, while it was not necessary for this exploration of the current vulnerability of the United Republic of Tanzania, extending the model to transport multimodality will be crucial for its application to more complex transport systems.

\section{Methods}

We model the road network of the United Republic of Tanzania, which carries more than $99.8 \%$ of the trade flows 9 . The continental part of the country consists of 25 regions and 169 districts. We leave the island regions of Zanzibar out of the scope of the study. Spatial distributions of gross domestic product (GDP) and population are used to locate 324 major transport nodes, called origin-destination (OD) nodes ${ }^{50,51}$. We estimate the production per sector and per district by using a business registry built and maintained by the National Bureau of Statistics of the United Republic of Tanzania that provides data on about 257,894 companies for the year 2017, including sector, administrative district and number of employees. We retain 42 sectors, based on the Global Trade Analysis Project (GTAP) classifications ${ }^{38}$. Corrections are applied using country-wide data on sectoral production ${ }^{38}$, spatially explicit GDP data ${ }^{51}$ and land cover data ${ }^{52,53}$. Final demand per district and per sector is estimated using population census and GTAP consumption data ${ }^{38,54}$. On each one of the 324 OD nodes, we model one representative household and, for each sector with substantial production at this node, one representative firm, leading to 1,962 representative firms. This setting allows us to represent the spatial distribution of population and activities along the national and regional roads. Because we aim at a country-level analysis, we do not model the last-mile accessibility to rural villages nor agricultural fields, which is best studied at the local level. Utilities and services are modelled differently because their outputs are not conveyed through the transport network as freight flows. We model country-wide representative firms for each one of these sectors and do not assign them to a specific OD node. Supplementary Figure 4 analyses the impact of the number of representative firms on the results.

Firms have a Leontief production function calibrated with GTAP input-output tables, as in the work of Henriet et al. ${ }^{31}$ and Inoue and Todo ${ }^{33}$. As opposed to Inoue and Todo ${ }^{33}$, we do not have the suppliers and buyers of each firm in the data. We reconstruct the supply chain links using a modified gravity model, based on the size, sector and location. For each sector from which they need input, representative firms randomly pick $s$ suppliers. For firm A of a relevant sector, the probability of being chosen as supplier by firm B grows with A's size and decreases with the distance between $\mathrm{A}$ and $\mathrm{B}$. This procedure allows the construction of the firm-to-firm network (see below for a discussion of the uncertainty created by this procedure). We assume that households only buy from firms located on the same OD node. For imports and exports, we explicitly model neighbouring countries with their border crossing and groups of non-neighbouring countries. For exports, countries choose the firms from which they buy based on their size. For imports, Tanzanian firms pick countries as suppliers based on the country's volume of exports to the United Republic of Tanzania and based on their distance to the country's entry point into the United Republic of Tanzania. Last, we build the country-to-country trade links for transit flows. Each one of these supplierbuyer relationships is associated with the lowest-cost path in the road network linking the OD node of the supplier to the OD node of the buyer. Given the final demand of households and countries, we can generate the map of the traded freight flows. Supplementary Figure 5 analyses the impact of the probabilistic network reconstruction on the results and the uncertainty created by the absence of data on the real firm-to-firm network (using 60 randomly generated networks, which is more than in Fig. 1 and confirms the robustness of the results).

The model is a discrete dynamic map $X_{t+1}=f\left(X_{t}\right)$, in which each time step represents a week. At each time step, firms plan production, order supplies, produce, adjust prices, deliver output and collect orders. These firm-level input-output dynamics build on the model of Henriet et al. ${ }^{31}$ Firms manage their inventory to maintain a target stock, which we calibrate using data from a survey made in 2018 of 800 Tanzanian firms. In the absence of perturbations, the model is at a steady state. When a node or a link of the transport network is disrupted, we model one of two mechanisms to capture the indirect economic losses, depending on whether an alternative pathway exists.

If an alternative pathway exists, supply chain flows are rerouted through the lowest-cost journey available, leading to higher-than-usual transport costs. Suppliers transfer these higher costs onto their clients by increasing their selling price. In turn, clients transfer such an increase in input costs to their own clients. Price increases propagate down to households and international buyers, which have to spend more for the same basket of goods.

If an alternative pathway does not exist, products that were supposed to be delivered are held at the producers' premises. If prolonged beyond the flexibility offered by inventories, this situation may lead to a shortage of inputs for clients and reduced production for them. At the end of the supply chains, households and international buyers may incur consumption losses due to scarcity of some inputs (valued at pre-shock prices)

Indirect losses are the sum of two economic impacts, namely spending due to increased transport costs and consumption loss due to scarcity in some goods and services. These two impact mechanisms-more expensive deliveries accepted by clients versus no deliveries, compensated by inventories-represent the two extremes of a continuous reality, in which firms adapt their purchase volumes to prices and product availability. As in Henriet et al. ${ }^{31}$, we assume that supply chains are fixed in the short term, that is, that firms do not switch to new suppliers within the few weeks of the simulation; however, they can adjust the quantities ordered from existing suppliers.

Our measure of indirect losses sums both impacts into a single monetary metric. For households, these impacts do not strictly represent monetary flows, but instead represent disruption-induced inflation (and therefore reduction in purchasing power) and scarcity in some goods and services in local markets. Similarly, the indirect losses for international buyers may not represent an actual added cost if international trade is highly competitive. However, they quantify a loss of competitiveness of Tanzanian exports.

To capture uncertainties related to the reconstruction of supply chain links, we simulate disruptions on multiple supply chain networks and average the estimates. We perform criticality analyses of the transport network. They consist of disrupting each transportation infrastructure one by one and measuring the associated indirect loss. We simulate disruptions that last for 1-4 weeks. For each duration, we perform statistical analysis based on the 300 most critical infrastructures. Supplementary Figure 5 shows the dispersion of the results due to the probabilistic reconstruction of the supply chain network. It shows that the identification of the most critical transport nodes and edges is robust to variations in the reconstructed networks.

The model is fully described in the Supplementary Methods, first formulating the model and then explaining how the data were processed to calibrate it.

\section{Data availability}

Input-output tables and international trade data were extracted from the GTAP database ${ }^{38}$. It is a licensed database provided by GTAP with restricted shareability, so the data are not publicly available. The firm registry and population census are data provided by the authorities of the United Republic of Tanzania. They are not publicly available; requests should be addressed to the National Bureau of Statistics of the United Republic of Tanzania. Gridded population data, spatial GDP data and spatial land cover data are available online; see references for direct links in CIESIN ${ }^{50}$, Kummu et al..$^{51}$ and RCMRD ${ }^{53}$. Inventories were estimated from a World Bank firm survey ${ }^{39}$. The survey results are not public data. They are, however, available from the authors upon reasonable request and with permission of the World Bank. The figure data are available at https://figshare.com/projects/ Criticality_analysis_of_a_country_s_transport_network_via_an_agent-based supply-chain_model/91367. The simulation data generated by the model are available from the corresponding author upon reasonable requests.

\section{Code availability}

The code of the model is available at https://github.com/ccolon/ disrupt-supply-chain-model, a Git repository maintained by the corresponding author.

Received: 23 March 2020; Accepted: 2 November 2020; Published online: 14 December 2020

\section{References}

1. NatCatSERVICE (Munich Re); https://natcatservice.munichre.com/

2. Preliminary sigma estimates for 2018: global insured losses of USD 79 billion are fourth highest on sigma records. Swiss Re Group https://www.swissre.com/ media/news-releases/nr 20181218 sigma estimates for 2018.html (18 December 2018).

3. Hallegatte, S., Rentschler, J. \& Rozenberg, J. Lifelines: The Resilient Infrastructure Opportunity, Sustainable Infrastructure Series (World Bank, 2019).

4. Kroll, C. A, Landis, J. D, Shen, Q. \& Stryker, S. Economic Impacts of the Loma Prieta Earthquake: A Focus on Small Business University of California Transportation Center Working Papers (University of California Transportation Center, 1991).

5. Kermanshah, A. \& Derrible, S. A geographical and multi-criteria vulnerability assessment of transportation networks against extreme earthquakes. Reliab. Eng. Syst. Saf. 153, 39-49 (2016).

6. Yang, S. et al. Criticality ranking for components of a transportation network at risk from tropical cyclones. Int. J. Disaster Risk Reduct. 28, 43-55 (2018).

7. Rozenberg, J, Briceno-Garmendia, C, Lu, X, Bonzanigo, L. \& Moroz, H. Improving the Resilience of Peru's Road Network to Climate Events Policy Research Working Paper (World Bank, 2017). 
8. Espinet Alegre, X., Rozenberg, J., Rao, K. S. \& Ogita, S. Piloting the Use of Network Analysis and Decision-making under Uncertainty in Transport Operations: Preparation and Appraisal of a Rural Roads Project in Mozambique under Changing Flood Risk and other Deep Incertainties Policy Research Working Paper (World Bank, 2018).

9. Pant, R., Koks, E. E., Russell, T. \& Hall, J. W. Transport Risk Analysis for the United Republic of Tanzania: Systemic Vulnerability Assessment of Multi-Modal Transport Networks (Oxford Infrastructure Analytics Ltd., 2018).

10. Mattsson, L.-G. \& Jenelius, E. Vulnerability and resilience of transport systems-a discussion of recent research. Transp. Res. Part A Policy Pract. 81, 16-34 (2015).

11. Chang, L., Elnashai, A. S. \& Spencer, B. F. Post-earthquake modelling of transportation networks. Struct. Infrastruct. Eng. 8, 893-911 (2012).

12. Barrot, J.-N. \& Sauvagnat, J. Input specificity and the propagation of idiosyncratic shocks in production networks. Q. J. Econ. 131, 1543-1592 (2016)

13. Fujimoto, T. Supply Chain Competitiveness and Robustness: A Lesson from the 2011 Tohoku Earthquake and Supply Chain 'Virtual Dualization' Discussion Paper Series No. 362 (Manufacturing Management Research Center, 2011).

14. Todo, Y., Nakajima, K. \& Matous, P. How do supply chain networks affect the resilience of firms to natural disasters? Evidence from the Great East Japan earthquake. J. Reg. Sci. 55, 209-229 (2015).

15. Boehm, C. E., Flaaen, A. \& Pandalai-Nayar, N. Input linkages and the transmission of shocks: firm-level evidence from the 2011 Tōhoku earthquake. Rev. Econ. Stat. 101, 60-75 (2019).

16. Haraguchi, M. \& Lall, U. Flood risks and impacts: a case study of Thailand's floods in 2011 and research questions for supply chain decision making. Int. J. Disaster Risk Reduct. 14, 256-272 (2015).

17. Chee Wai, L. \& Wongsurawat, W. Crisis management: Western Digital's 46-day recovery from the 2011 flood disaster in Thailand. Strategy Leadersh 41, 34-38 (2013).

18. Haimes, Y. Y. et al. Inoperability input-output model for interdependent infrastructure sectors. I: Theory and methodology. J. Infrastruct. Syst. 11, 67-79 (2005).

19. Okuyama, Y. Modeling spatial economic impacts of an earthquake: input-output approaches. Disaster Prev. Manag. 13, 297-306 (2004)

20. Kelly, S., Tyler, P. \& Crawford-Brown, D. Exploring vulnerability and interdependency of UK infrastructure using key-linkages analysis. Netw. Spat. Econ. 16, 865-892 (2016).

21. Rose, A. \& Liao, S.-Y. Modeling regional economic resilience to disasters: a computable general equilibrium analysis of water service disruptions. J. Reg. Sci. 45, 75-112 (2005).

22. Hallegatte, $S$. An adaptive regional input-output model and its application to the assessment of the economic cost of Katrina. Risk Anal. 28, 779-799 (2008)

23. Kurth, M. et al. Lack of resilience in transportation networks: economic implications. Transp. Res. D Transp. Environ. 86, 102419 (2020).

24. Chen, Z. \& Rose, A. Economic resilience to transportation failure: a computable general equilibrium analysis. Transportation 45, 1009-1027 (2018).

25. Hallegatte, S, Vogt-Schilb, A, Bangalore, M. \& Rozenberg, J. Unbreakable: Building the Resilience of the Poor in the Face of Natural Disasters (World Bank, 2017).

26. Norrman, A. \& Jansson, U. Ericsson's proactive supply chain risk management approach after a serious sub-supplier accident. Int. J. Phys. Distrib. Logist. Manag. 34, 434-456 (2004).

27. Sheffi, Y. The Resilient Enterprise: Overcoming Vulnerability for Competitive Advantage (MIT Press, 2005).

28. Acemoglu, D., Carvalho, V. M., Ozdaglar, A. \& Tahbaz-Salehi, A. The network origins of aggregate fluctuations. Econometrica 80, 1977-2016 (2012).

29. Colon, C. \& Ghil, M. Economic networks: heterogeneity-induced vulnerability and loss of synchronization. Chaos 27, 126703 (2017).

30. Gabaix, X. The granular origins of aggregate fluctuations. Econometrica 79, 733-772 (2011).

31. Henriet, F., Hallegatte, S. \& Tabourier, L. Firm-network characteristics and economic robustness to natural disasters. J. Econ. Dyn. Control 36, 150-167 (2012).

32. Welburn, J. W. et al. Systemic Risk in the Broad Economy: Interfirm Networks and Shocks in the US Economy Research Reports (RAND Corporation, 2020)

33. Inoue, H. \& Todo, Y. Firm-level propagation of shocks through supply-chain networks. Nat. Sustain. 2, 841-847 (2019).

34. Kim, T. J., Ham, H. \& Boyce, D. E. Economic impacts of transportation network changes: implementation of a combined transportation network and input-output model. Pap. Reg. Sci. 81, 223-246 (2005).

35. Ham, H., Kim, T. J. \& Boyce, D. Assessment of economic impacts from unexpected events with an interregional commodity flow and multimodal transportation network model. Transp. Res. Part A Policy Pract. 39, 849-860 (2005).

36. Tatano, H. \& Tsuchiya, S. A framework for economic loss estimation due to seismic transportation network disruption: a spatial computable general equilibrium approach. Nat. Hazards 44, 253-265 (2008).
37. OpenStreetMap contributors Planet dump (Planet OSM, 2019); https://planet. osm.org

38. Aguiar, A., Narayanan, B. \& McDougall, R. An overview of the GTAP 9 data base. J. Glob. Econ. Anal. 1, 181-208 (2016).

39. Rentschler, J., Kim, E., Thies, S. \& De Vries Robbe, S. Urban Flooding and Firm Performance: Evidence from a Survey of Tanzanian Firms (World Bank, in the press).

40. Colon, C., Hallegatte, S. \& Rozenberg, J. Transportation and Supply Chain Resilience in the United Republic of Tanzania: Assessing the Supply-Chain Impacts of Disaster-Induced Transportation Disruptions Background study to LIFELINES: The Resilient Infrastructure Opportunity (World Bank, 2019).

41. Iimi, A., Humphreys, R. M. \& Mchomvu, Y. E. Rail Transport and Firm Productivity: Evidence from Tanzania Policy Research Working Paper 8173 (World Bank, 2017).

42. No. 7183546 Overview of Engineering Options for Increasing Infrastructure Resilience (Miyamoto International, 2019).

43. Bosio, E., Arlet, J., Nogues Comas, A. A. \& Anouk Leger, N. Data from: Road Cost Knowledge System (ROCKS): Update (Doing Business and World Bank, 2018).

44. Kornejew, M., Rentschler, J. E. \& Hallegatte, S. Well Spent: How Governance Determines the Effectiveness of Infrastructure Investments Policy Research Working Paper 8894 (World Bank, 2019).

45. Guasch, J. L. \& Kogan, J. Just-in-Case Inventories: A Cross-Country Analysis. Policy Research Working Paper 3012 (World Bank, 2003).

46. Rozenberg, J. \& Fay, M. Beyond the Gap: How Countries Can Afford the Infrastructure They Need while Protecting the Planet (World Bank, 2019).

47. Akbari, V. \& Sibel Salman, F. Multi-vehicle synchronized arc routing problem to restore post-disaster network connectivity. Eur. J. Oper. Res. 257, 625-640 (2017).

48. Kashiwagi, Y., Todo, Y. \& Matous, P. International Propagation of Economic Shocks through Global Supply Chains. WINPEC Working Paper Series No. E1810 (WINPEC, 2018).

49. Baldwin, R. E. \& Evenett, S. J. COVID-19 and Trade Policy: Why Turning Inward Won't Work (CEPR Press, 2020).

50. Center for International Earth Science Information Network, Columbia University Gridded Population of the World, Version 4 (GPWv4): Population Density, Revision 10 (NASA Socioeconomic Data and Applications Center (SEDAC), 2017; https://doi.org/10.7927/H4DZ068D

51. Kummu, M., Taka, M. \& Guillaume, J. H. Dryad Data from: Gridded globa datasets for Gross Domestic Product and Human Development Index over 1990-2015 (Dryad Digital Repository, 2020); https://doi.org/10.5061/dryad. dk1j0

52. Laso Bayas, J. et al. Validation of automatically generated global and regional cropland data sets: the case of Tanzania. Remote Sens. 9, 815 (2017).

53. Tanzania Land Cover 2010 Scheme II (RCMRD, 2015, accessed 25 October 2019); http://geoportal.rcmrd.org/layers/servir\%3Atanzania_landcover_ 2010_scheme_ii

54. Tanzania Census 2012 (Data for All, accessed 25 October 2019); http://dataforall.org/dashboard/tanzania/

\section{Acknowledgements}

We thank J. F. Arvis, R. M. Humphreys and J. Rentschler for their constructive comments and J. Rentschler and A. Erman for facilitating access to Tanzanian data and for carrying out the firm survey. The study was supported by the Global Facility for Disaster Reduction and Recovery and the International Institute for Applied System Analysis.

\section{Author contributions}

C.C., J.R. and S.H. designed the study, formulated the model and wrote the paper. C.C. developed the model, processed input data, ran and analysed simulations and prepared the manuscript.

\section{Competing interests}

The authors declare no competing interests.

\section{Additional information}

Extended data is available for this paper at https://doi.org/10.1038/s41893-020-00649-4. Supplementary information is available for this paper at https://doi.org/10.1038/ s41893-020-00649-4.

Correspondence and requests for materials should be addressed to C.C

Peer review information Nature Sustainability thanks Sybil Derrible and the other, anonymous, reviewer(s) for their contribution to the peer review of this work.

Reprints and permissions information is available at www.nature.com/reprints. Publisher's note Springer Nature remains neutral with regard to jurisdictional claims in published maps and institutional affiliations.

(c) The Author(s), under exclusive licence to Springer Nature Limited 2020 


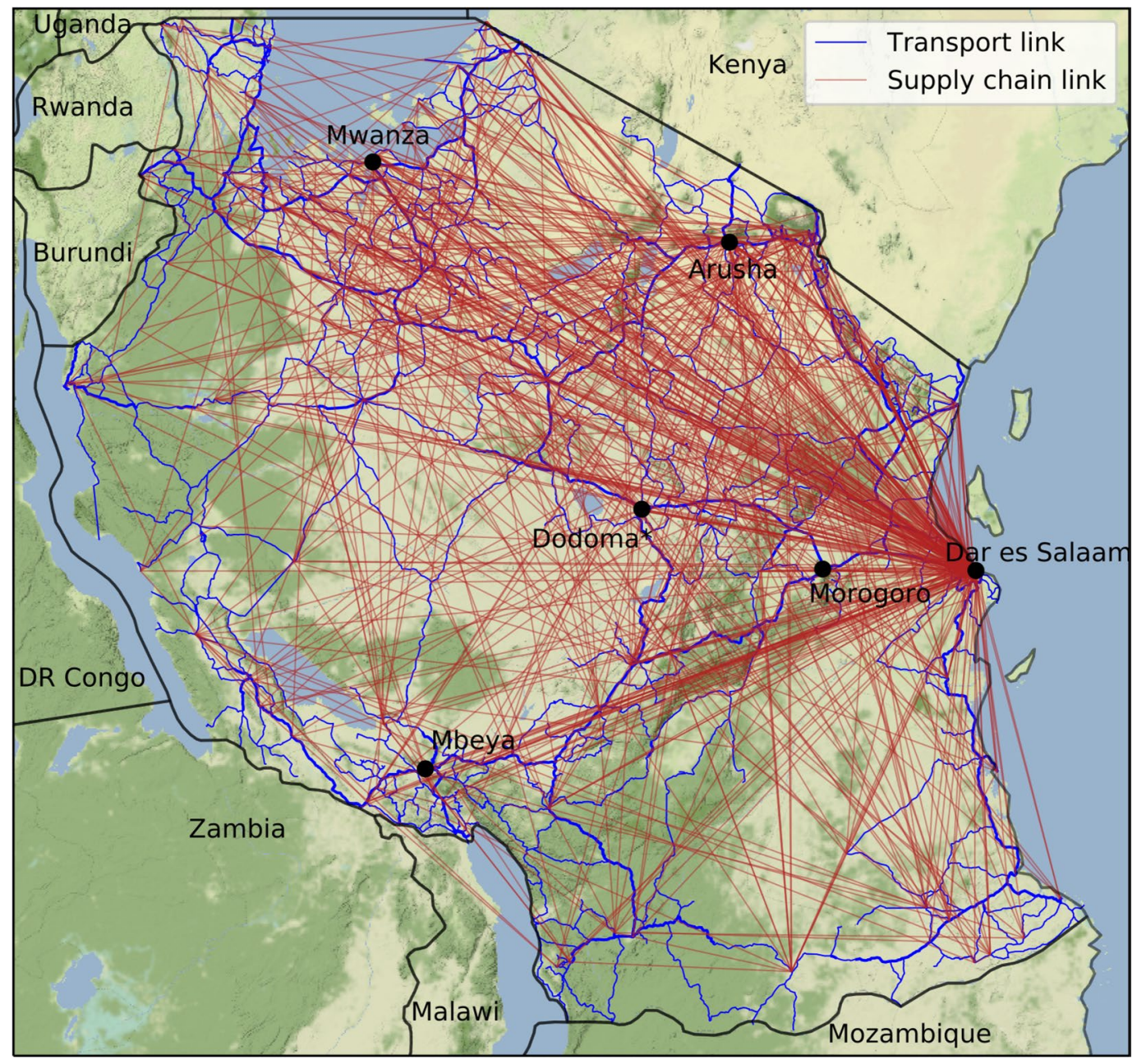

Extended Data Fig. 1 | Coupling the interfirm (red) and transport (blue) networks. The red straight lines represent the 10\% largest supply-chain links, in monetary terms, between the modeled Tanzanian firms. Those links belong to one of the reconstructed interfirm networks used in the simulations; see Supplementary Method 2.5.2. The blue lines represent the transport network from road data; see Supplementary Method 2.1.1. Map tiles by Stamen Design, under CC BY 3.O. Data by OpenStreetMap, under ODbL. 

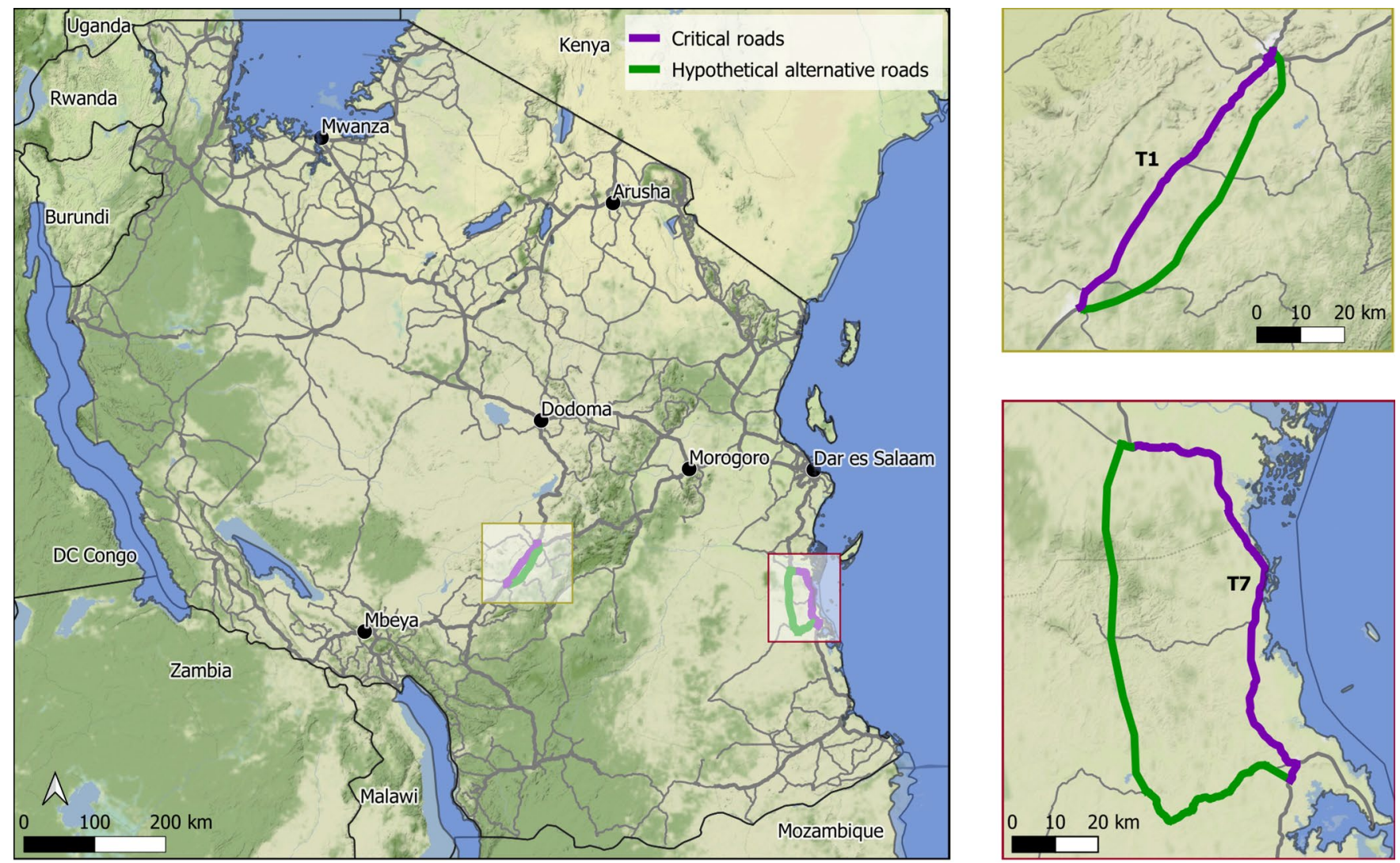

Extended Data Fig. 2 | Map of the interventions evaluated in Main Text's Fig. 3. They target a portion of the T1 road (top right map) and a portion of the T7 road (bottom right map). The thick purple lines represent the targeted critical roads, which are made more resistant in intervention (a-i) of Fig. 3 , and for which the recovery services are improved in intervention (a-iii). The thick green lines indicate hypothetical alternative roads evaluated under intervention (a-ii). They were designed to offer an alternative in case of disruption of the critical roads. They are purely hypothetical and are not related to any real-world project. Map tiles by Stamen Design, under CC BY 3.0. Data by OpenStreetMap, under ODbL. 
(iii) Closer suppliers

$40 \%$
ㄱ 1-week disruptions
ㅁ 4-week disruptions

$20 \%$

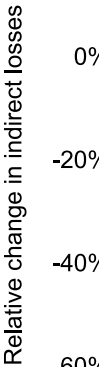

$-80 \%$

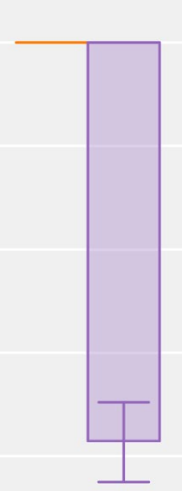

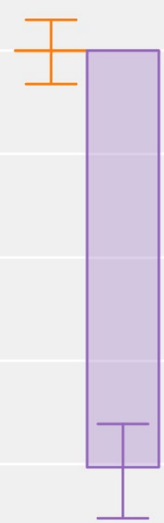

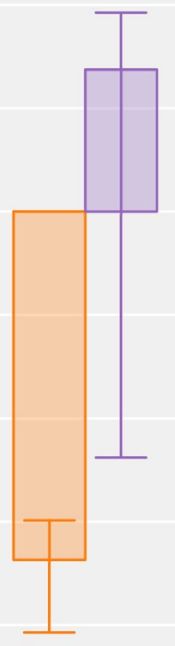

Extended Data Fig. 3 | Demand-side management of transport disruptions. The same demand-side interventions as in Main Text's Fig. 3b are evaluated, but on the 300 most critical transport nodes, whereas Fig. 3b focused on the specific roads highlighted in purple in Extended Data Fig. 2. The interventions are: (i) all firms hold one more week of inventories, (ii) all firms have two suppliers per type of inputs instead of one, and (iii) the distance between suppliers and buyers is on average $60 \mathrm{~km}$ instead of $190 \mathrm{~km}$. Each rectangle extents to the mean of the distribution, the bar indicates the interquartile interval. 
(a) One-week disruptions

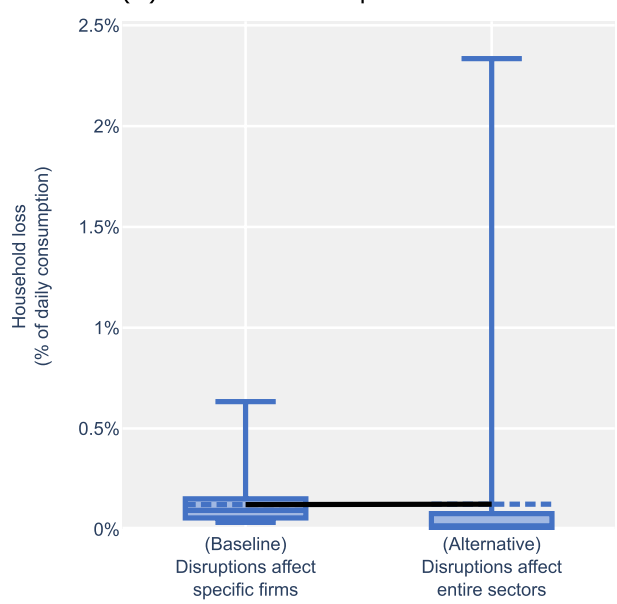

(b) Four-week disruptions

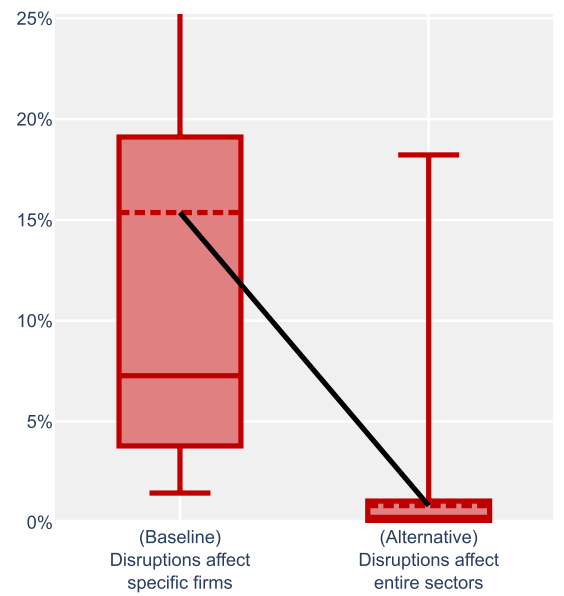

Extended Data Fig. 4 | Cost amplification is larger when disruptions are modeled at the level of firms rather than sectors. In both panels, the bars on the left (baseline) represent the distribution of indirect losses resulting from the disruptions of the 300 most critical transport nodes, modeled as in the remainder of the study. For the other bars (alternative), the direct impacts of those disruptions are no longer applied to the firms located in the disrupted nodes but are evenly distributed on all the firms of the affected sectors. For instance, say that firm 1 of sector $A$ is directly affected, preventing it from delivering a certain amount of sector-A goods in the baseline. In the alternative case, this amount is transformed into a decrease in production capacity applied to all sector-A firms across the country. The direct impact is quantitively the same but distributed differently. This alternative behavior represents what is implied by sector-level input-output analysis. The filled rectangle indicates the interquartile interval; the solid horizontal lines indicate the median; the horizontal dash line indicates the mean. Mean values are joined with a black curve. The vertical line extends to the minimum and maximum of the distributions; when the maximum lies outside the plotting area, as in (b), the upper part of the vertical line is not capped. 


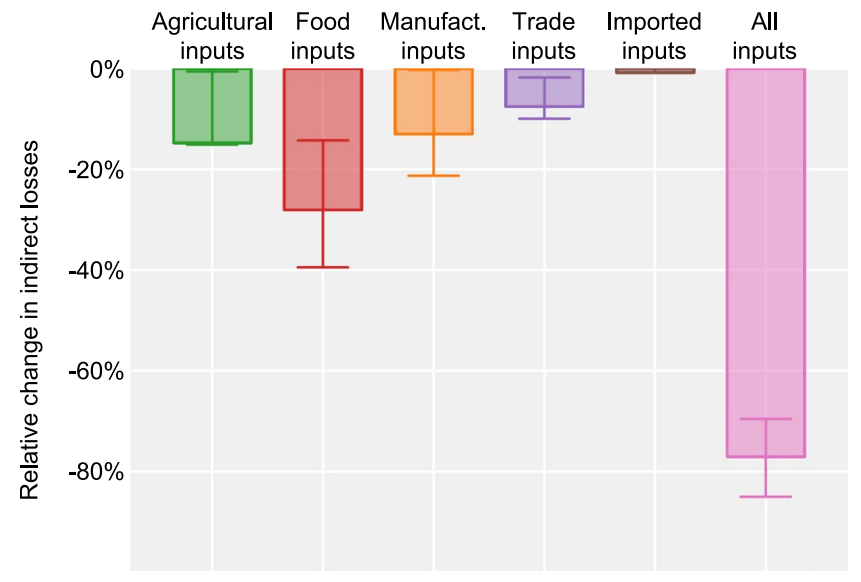

Extended Data Fig. $\mathbf{5}$ | Inventories of food products are most effective in reducing indirect losses. Each rectangle extends to the average relative change in indirect losses that results from a one-week increase in inventories for specific categories of inputs. This increase concerns all firms across the countries. Vertical bars indicate interquartile intervals. Four-week disruptions of the 300 most critical transport nodes are simulated. Results are averages over ten network reconstructions. 